\title{
Afriphone Literature as a Prototypical form of African Literature: Insights from Prototype Theory
}

\author{
Adams Bodomo \\ Department of African Studies, University of Vienna, Spitalgasse 2, Hof 5, 1090 Vienna, Austria \\ E-mail: adams.bodomo@univie.ac.at
}

Doi:10.7575/aiac.alls.v.7n.5p.262

URL: http://dx.doi.org/10.7575/aiac.alls.v.7n.5p.262
Received: 11/07/2016

Accepted: 27/08/2016

\begin{abstract}
What is the most prototypical form of African literature? Shouldn't we be using African languages to produce African literary texts, shouldn't we produce more Afriphone African literature compared to Europhone African literature or Afro-Europhone literature? This issue underlies the reality that the vast majority of African writers presumably think in one language and express themselves (speak, enchant, or write) in another. This problematic, crystalized in major debates between Ngugi wa Thiongo and others, on the one hand, and Chinua Achebe and others, on the other hand, has resulted in great challenges as to how we can define or even conceptualize the discipline of African literature. Is it literature written by Africans in African languages for Africans or is it literature written by anybody including nonAfricans in non-African languages? Or is it somewhere in-between these two extremes? The paper discusses several positions on this major question in African literature before advancing a novel proposal based on insights and evidence from proto-type theory within Linguistics and the Cognitive Sciences. This proposal leads to a somewhat provocative conclusion about the gradation of African literatures, where African language literatures or Afrophone literatures, comprise the core, proto-typical category in a $21^{\text {st }}$ Century African literature constellation, whereas foreign language and diasporic literatures such as Afro-European literatures, Afro-American literatures, and Afro-Chinese literatures are the hybrid and thus more recessive, peripheral types of African literature.
\end{abstract}

Keywords: Afriphone literature, African language literature, African literature, proto-type theory, linguistics, cognitive Science

\section{Introduction ${ }^{i}$}

A long standing debate within African literature and indeed in much of Africa's linguistic expressive discourse is whether it is best to use African languages or the former colonial European languages in African literary writing and general academic discourse. More specific questions include the following: Are English, French and other foreign languages appropriate for Africa literature? Can we still refer to a piece of work as African literature if it is not written in an African language? Two major positions, each representing either side of the debate, are often advanced. One position claims that African languages are central to African literary expressions and should be the ones we should naturally use for writing and encoding African literature, whereas the other says that, given our colonial past which has led to much European language literacy education and given Africa's complex multilingual situation, we are better off using the former colonial languages English, French, and Portuguese in producing African literature. There are, however, minor positions that try to reconcile the two major positions and suggest that this should not be an 'either...or' issue but a 'both' issue. However, more questions still remain beyond attempts to reconcile the two major positions in the debate. This paper carefully looks at either side of the debate before making some proposals that draw in insights from linguistics and cognitive science to suggest ways in which we can align the plethora of languages used in Africa to understand what African literature is or ought to be.

\section{Literature review: the language question}

To even begin to tackle the debate surrounding the question of what language to use in African literature we need to decide for ourselves what African literature is or should be in the first place.

\subsection{What is African literature?}

Literature has many definitions and conceptualizations but it usually involves a form of artistic creation by an individual or group of individuals with language (written, spoken, or enchanted) that attempts to represent some conceptualization of a possible world, real or imagined. We will now put forward a working definition and gradually modify it in account of our discussions until we conclude the paper with a more definitive definition.

i. African literature then would presumably be literature as defined above that is created by an African (as opposed to a non-African) to represent some aspect of the African world, real or imagined.

The difficulty created in the above definition would lie with establishing who an African is and what this African world is. 
As a result, we need to revise the definition to address these problems.

ii. African literature is a form of artistic creation produced in the medium of language (written, spoken, or enchanted) by an artist or group of artists with African experiences to represent some aspect of the African world.

This basic definition can be extended to specify what language is used and what we mean by African world. We do not need to belabour the issue of who an African is because we are not requiring the artist to be a citizen of any of the countries on the African continent or even be born there but to have African experiences of significant degree, meaning to have experienced and understood some sociocultural aspects of the African world in order to be able to express and represent them artistically.

What we need to specify are the issue of 'language', the very subject matter of our discussion here, and the issue of 'African world'. We will be non-committal about language in the current working definition and at the end of the paper we will then decide how to specify this. We will also try to extend the issue of "African world" to mean the landscape of the continental landmass of Africa and all the cultures represented on this landmass and its associated islands along with diasporic exportations of the cultures of the continental landmass.

iii. African literature is a form of artistic creation produced in the medium of any natural language (written, spoken, or enchanted) by an artist or group of artists with substantial enough experiences of the landscape of the continental landmass of Africa and its associated islands, along with diasporic exportations of the cultures of this continental landmass.

It should be easy to delineate this continental landmass because it is neutral in terms of geographical reality with clear enough sea and land boundaries. It doesn't say anything about nations or people because every group of people living on the African continent is subsumed under this definition, unless of course they want to opt out, in which case it would then be a personal or group identity exceptionalism to which they are entitled.

There are, at least, two things we can do to this definition. We could make a catalogue of any group of literary artistic creations and then try to see if we can include or exclude them as African literature on the basis of this definition. Consider the following literary works: Things fall Apart by the Nigerian Chinua Achebe, Une Si Longue Lettre by the Senegalese Mariama Ba, and Heart of Darkness by the Polish-British Joseph Conrad. Variable parameters will include origins and identity of the author (what are the citizenship, gender, cultural background of the author?), setting of the work of art (is it mainly on the African continent?), themes of the work of art (is it expressing some aspect of the society or culture of the African geographical landmass?), language (what language is used, is it indigenous to the African continent?). The first two books are by Africans while the third is by a European. All three books deal with African themes in an African setting. All the books are written in the non-African languages English and French. The acceptance of these as works of African literature would then depend on how we answer the questions posed throughout this paper.

Another approach to take is to compare the definition and conceptual sketch of African literature presented here with the definitional conceptualization by Ayuk (2014). While acknowledging the similarities between world literatures, the Ayuk's work tries to list some common features of African literature: the pervasive use of proverbs; plot - abrupt exposition of conflict between man and man, man and society but rarely man and self; character - the recurrent use of the concept of tragic hero; and some very common themes like nudity (where Africans believe distinctly that nudity begins and ends with genitals only), polygyny, time - the notion of African time, jungle justice, Christianity against animism, corruption, and colonialism.

\subsection{Chinua Achebe versus Ngugi wa Thiong'o}

But these definitions still leave room for a debate on which is the most appropriate language to use in African literature. Ngugi (1986) makes a convincing case for the use of only African languages in his major work, Decolonizing the Mind. He details the circumstances that led him from abandoning writing in English in favour of writing in his mother tongue Gikuyu and in the East African lingua franca, Swahili in 1977. On this basis alone none of the three works by Achebe, $\mathrm{Ba}$ and Conrad would qualify as African literary works since they are not written in African languages. He decries the fact that most African authors write in foreign languages - the language of the imperialists - languages that were relatively imposed on them. He is convinced that there is a need to create a literature that conveys the true African experience from the perspective of the local, not the visitor or outsider. He believes strongly that what African writers have created so far is a hybrid tradition that can only be termed Afro-European literature, and not real African literature. He asserts "How we view ourselves/our environment is very much dependent on where we stand in relationship to imperialism in its colonial and neo-colonial stages." (1986, p. 88).

Indeed, Ngugi has maintained these positions throughout the years as crystalized in a recent British Broadcasting Corporation (BBC) interview (HardTalk, 2013), where he even challenges that somehow surprising notion from some people that English is an African language as contained in the following exchange between the interviewer and Ngugi:

Q: You wrote very adequately in Decolonizing the Mind that [while] the bullet was the means of physical subjugation, language was a means of spiritual subjugation ... and that's part of the journey of your life to write not in English for your novels, but to write in Kikuyu. Why did you take that decision? You took it in prison, didn't you?

A: Language is so basic to any community. What I found is very interesting, whenever one people have colonialized another, they always impose their language, whether the French, the Portuguese, any... 
Q: And you took ironically the decision while you were imprisoned by arap Moi after the colonial powers had left. That was a Kenyan that put you in prison, because you were a dangerous writer.

A: The whole point about language is that after some time it will become what is called a metaphysical empire, the empire of the mind. Language is central to the whole idea of metaphysical empire. ... For me all languages are wonderful, be it Swahili, Kikuyu. But the problem has been, in a system of oppression and aggression, it's a hierarchy of power relationship between languages. Not which language is better, it's which language is higher than the other.

Q: I wondered, you know, the great African writer Chinua Achebe, he suggested that it wasn't quite the case as you put it, but also Ngozi Adichie, a younger Nigerian writer - she says, "English is my language". She's taken over it. I just wonder whether your views were very much of that time of the fifties and the sixties... and the younger African writers take a different view.

A: English is not an African Language. Full stop. One can say we adapted it, so on. In Nigeria there's Yoruba, Igbo, in Kenya there's Kikuyu, Luo. We have genuine African languages.

Q: But Chimamanda Ngozi Adichie says "English is mine. I've taken ownership with English". So she's kind of decolonized herself in a different way, hasn't she?

A: No. She's part of the metaphysical empire. Metaphysical empire is when people now begin to claim that this space is really mine. That doesn't mean that what she and my son Mukoma do with English isn't wonderful. But when we do that we're contributing to the expansion and deepening of the English language, not the Yoruba or Kikuyu or Kiswahili.

Q: You translate your own works into English. So, isn't that contributing?

A: No, translation is a very important process of how languages and cultures communicate. Look at the contribution of translations to the rise of European literature and languages.

It is very clear from the above sources that Ngugi wa Thiong'o excludes any writing in English, French, Portuguese, Chinese, Japanese or any other foreign language as being African literature.

Chinua Achebe, the author of one of the most famous novels to come out of Africa, Things Fall Apart, takes a completely different view from Ngugi wa Thiog'o. In a response to Ngugi's positions in Decolonizing the Mind, which Achebe considers as a criticism of him and other writers who write in European languages, Achebe in Politics and Politicians of Language in African Literature (this title itself being a literary indirection deployed against Ngugi since the sub-title of Decolonizing the Mind is 'the Politics of Language") states:

"I write in English. English is a world language. But I do not write in English because it is a world language. My romance with the world is subsidiary to my involvement with Nigeria and Africa. Nigeria is a reality which I could not ignore." (1989, p. 100)

From the above confrontation between Achebe and Ngugi we see that the vast majority of Africans speak one language and write in an entirely different language. This issue underlies what the Ivorian writer, Amadou Kourouma, terms as 'diplosie' (Kourouma, 1991, p. 43), the reality that the vast majority of African writers presumably think in one language and express themselves (speak, enchant, or write) in another. It looks as if we are in a dichotomous situation, an "either...or" situation where African literature is defined in terms of whether or not a piece of writing is truly African literature depending on its medium of expression. It seems this debate has come to a stalemate.

In this paper, I wish to revive it with a relatively new perspective, bringing in contributions from proto-type theory as espoused in studies within Linguistics and Cognitive Science.

\section{Contributions from Linguistics and Cognitive Science}

In works within linguistics and the cognitive sciences (e.g. Rosch, 1977; Wittgenstein, 2001; Taylor, 2003), there is a growing trend whereby the classical, definitional approach to categorization within which something either absolutely belongs to a category or doesn't is less favoured to approaches where we think of a gradational approach to group membership. In this approach some group members are more prototypical than others depending on the fact that they have more features of the group than others. We shall espouse this position with a number of illustrations and then use that to address the language question in African literature.

\subsection{Categorization}

Humans have the linguistic and cognitive abilities to categorize things in the world (Rosch, 1977; Wittgenstein, 2001; Taylor, 2003; Miyamoto, 2013). We may categorize objects in the physical world such as tables, chairs, cars, dogs, cats; types of people such as teachers, friends, black, white; and abstract categories such as theft (Miyamoto, 2013).

We may do this by using the definitional approach to category membership, where a category would emphasize the set of all things that are joined together under a common label, and this definitional approach is established or determined by checking a list of all necessary and sufficient features (Miyamoto, 2013) that account for the concept.

But as Rosch (1977) the linguist and cognitive scientist observes, the weakness to the definitional approach is that we are not told how we discover definitions and thus it does not explain important aspects of the processes of human categorization. 


\subsection{Prototype Theory of Categorization}

Rosch (1977) instead proposes a prototype theory of categorization whereby categories have prototypes - category structure is created by the relationship between category members and the category prototype (Rosch, 1977; Taylor, 2003; Miyamoto, 2013). A prototype to these scholars is a mental representation of a concept which retains the typical characteristics of many particular examples; and categorization decisions are based on the similarity of a specific instance to the prototype of a category (Rosch, 1977; Taylor, 2003; Miyamoto, 2013). As Miyamoto (2013) indicates, the concept of a cat would be some animal that has the features as listed in Diagram 1; then any members of the cat family will have more or less the features indicated, with the prototypical members exhibiting more of these features.

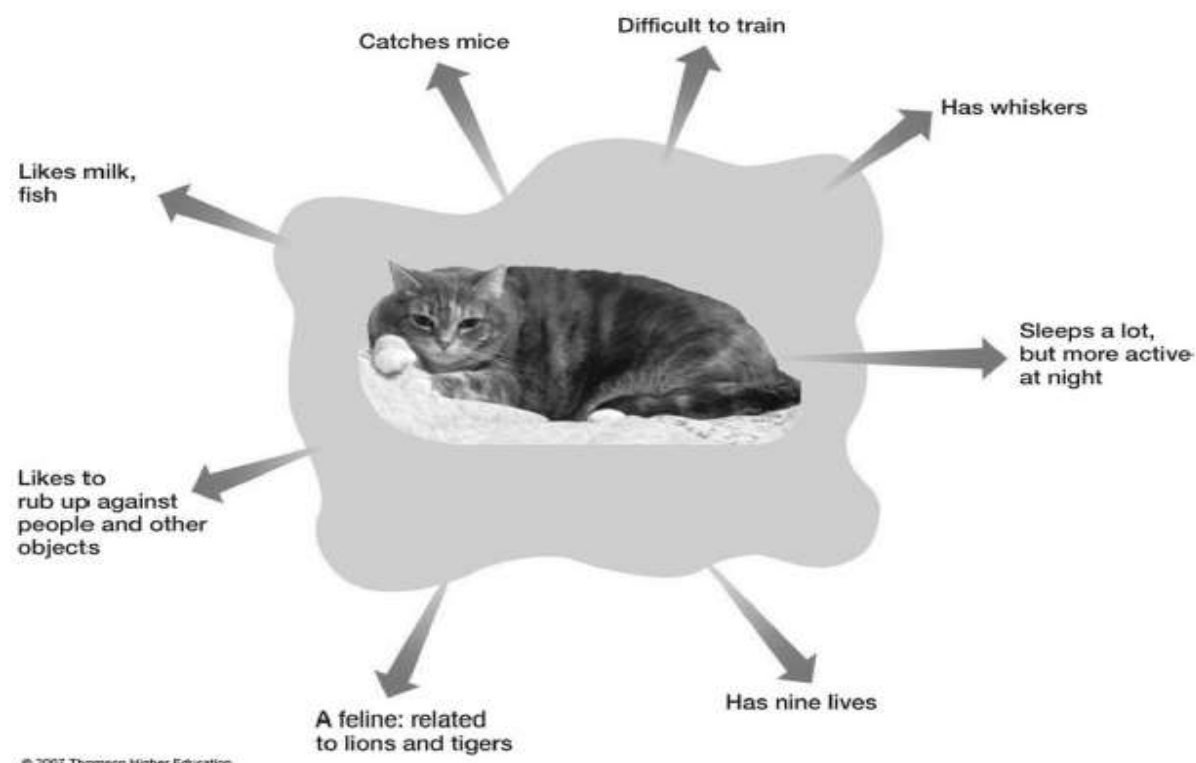

(Source: Psychology 355: Cognitive Psychology, Instructor: John Miyamoto, 02/26/2013: Lecture 8-1)

Diagram 1

Evidence for the prototype approach to categorization has been found from various semantic memory experiments within Cognitive Science. The idea is that subjects are faster to verify that prototypical objects are in the category than non-proto-typical objects (Rosch, 1977; Taylor, 2003; Miyamoto, 2013). For instance if one is asked to name prototypical categories of furniture in a room in an experiment, subjects are likely to mention chair, table, stool, desk, but hardly a computer or a wooden piece of artwork hanging on the wall (Bodomo, 2013) ${ }^{\mathrm{ii}}$.

\subsection{Prototype Experiment with List of Languages}

With particular reference to our current topic, if people are asked to list African languages or identify the most prototypical African languages in a list, English, French and Portuguese will not be the first to be listed nor will they be high on the list, if at all they are listed.

We did a proto-type experiment involving the administration of questionnaires to 200 people of all ages and nationalities in Vienna and London between February 2014 and April 2014, with more than half being Africans (Bodomo, 2014) $)^{\mathrm{iii}}$, asking them to identity a list of languages, either as being African or not being African. Here are the results:

Which of the following languages, in your opinion, are African languages?

\section{African Languages}

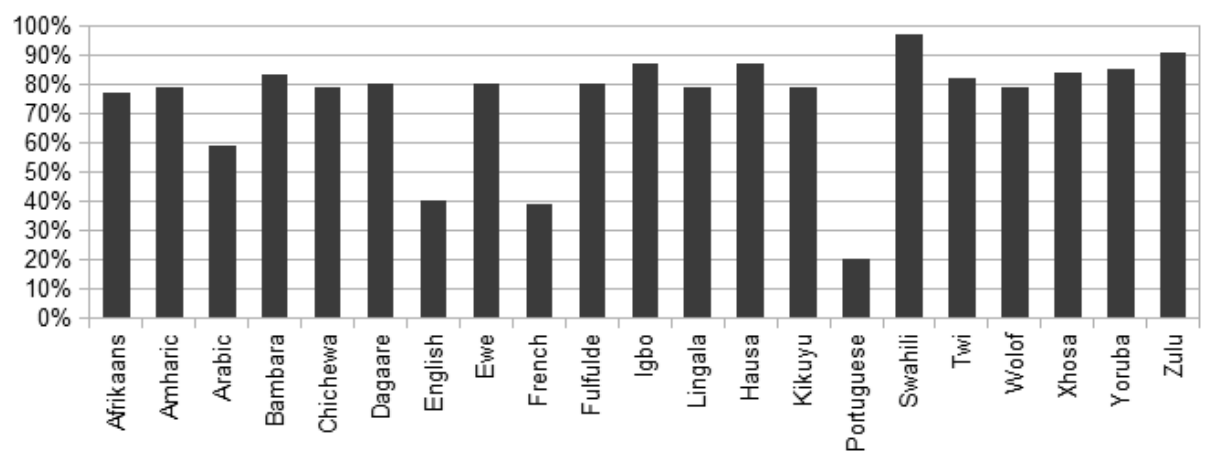

Diagram 2

Which of the following languages, in your opinion, are NOT African languages? 
'Not' African Languages

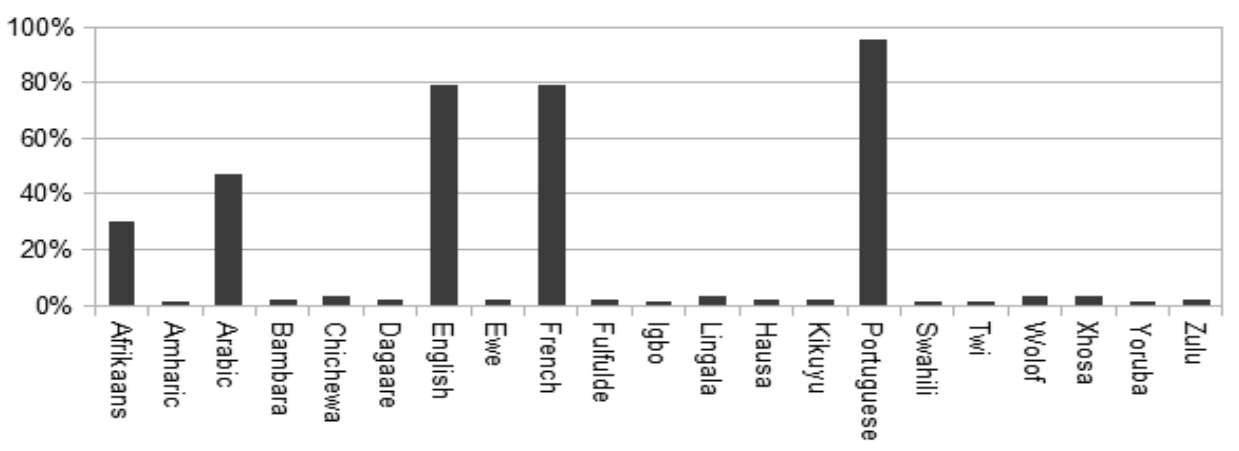

Diagram 3

As can be seen, even though the former colonial languages are listed as African languages in diagram 3 (20\% for Portuguese and $40 \%$ each for English and French) they have the lowest percentages when subjects were asked to identify items on the list that are African languages. This means that these colonial languages, in line with the prototype theory, are African languages but they are not proto-typical African languages.

This is further confirmed by the answers given when subjects are asked to identify members of a list of languages that are not African languages (diagram 4). The former colonial languages have the highest percentages (98\% for Portuguese and $80 \%$ each for English and French), again suggesting that they are not really proto-typical members in the category of African languages.

How does this discussion from prototype theory inform us about this classical debate about the definition of African literature with respect to the language of expression? The classical debate, as we have seen in the case of Achebe and Ngugi, has taken the form of a dichotomy, an "either ... or" scenario. But this is contrary to proto-type theory which informs that we are better off taking a more gradational approach, a more nuanced, proto-typical approach to membership categorization. With this in mind we may now redefine African literature in section 4.

\section{Redefining African literature: pluralizing literature}

In our working definition of African literature we came up with the following:

African literature is a form of artistic creation produced in the medium of any natural language (written, spoken, or enchanted) by an artist or group of artists with substantial enough experiences of the landscape of the continental landmass of Africa and its associated islands, along with diasporic exportations of the cultures of this continental landmass.

But it is clear that, though any language may be used as a medium of African literary production, those languages that are more able to express African cultures and African experiences of the continental landscape of Africa should be more prominent in expressing African literature. These languages should be more prototypical than the others, in line with the proto-type theory.

Therefore we may come up with the following diagram of African literatures and the language question where African languages occupy the centre:

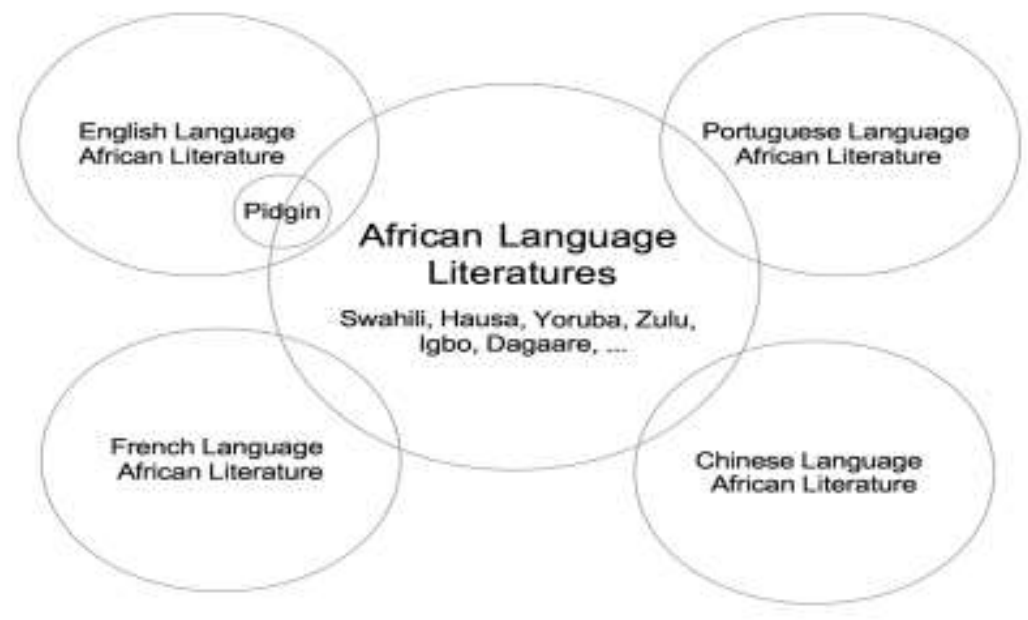

Diagram 4

In this approach, as illustrated in diagram 4, we do not necessarily exclude the idea that any language can be used to express African literature, we express the idea that some languages are more natural, more prototypical in the 
expression of African literature and African culture in general. Hence we have African language literatures at the centre, these are the most proto-typical. Then comes along other types of African literature: English language-based African literature (Anglophone African literature), French language-based African literature (Francophone African literature), Portuguese language-based African literature (Lusophone African literature), and in a rather hypothetical but predictive scenario in the near future, Chinese language-based African literature (Sinophone African literature), given that there is now a huge number of Chinese speakers in Africa in the region of two million.

It is possible that pidgin-based forms of African literature may begin to emerge as shown on the diagram, and indeed, the works of the Nigerian writer Amos Tutuola in The Palm Wine Drinkard, is a typical example of this kind of literature.

In short, then, the consequences of this approach using proto-type theory is that we must now accept the fact that there are several types of African literature depending on which group of languages we use:

African language literatures (Akan, Dagaare, Hausa, Igbo, Swahili, Yoruba, Zulu, etc. literatures)

European language African literatures (African literature in English, French, German, etc.)

Asian language African literatures (African literature in Chinese, Japanese, Hindi, Korean, etc.)

This approach means that we can now afford to finally redefine African literature, putting African languages at the centre of the constellation:

African literature is any form of artistic creation produced in the medium of African languages, first and foremost, or any other natural language (written, spoken, or enchanted) by an artist or group of artists with substantial enough experiences of the landscape of the continental landmass of Africa and its associated islands, along with diasporic exportations of the cultures of this continental landmass.

\section{Conclusion: Towards an agenda for African language literature}

In conclusion, we now have a pluralized agenda for African literature; we can no longer talk of African literature but African literatures. There are consequences for evolving such a pluralized agenda in terms of priorities.

Since resources are scarce and we cannot continue to do any type of African literature in an unlimited way the question of priority and prioritization now has to set in. Since, so far, we have shown by the application of prototype theory that, ceteris paribus, African languages are the prototypical and more natural media through which African literature should be produced, the only logical thing is to evolve a research agenda whereby African languages would be at the centre of African literary research.

Africans of all walks of life and sympathetic Africanists must evolve an agency agenda to ensure that Afriphone literatures take hold in the $21^{\text {st }}$ Century.

\section{References}

Achebe, C. (1989). Politics and Politicians of Language in African Literature. In G.D. Killam, \& R.E. Happy (Eds.), Historical and Cultural Contexts of Linguistic and Literary Phenomena. Canada: University of Guelph.

Ayuk, H. (2014). What is African literature? [Online]

Retrieved from http://princehamilton.blogspot.co.at/2009/06/what-is-african-literature.html (June 6, 2014).

Kourouma, A. (1991). Comments. In F. Osofisan, et al. (Eds.) Proceedings of the International Symposium on African Literatures, 2-7 May 1988, Lagos, Nigeria = Compte rendu du Colloque sur les litteratures africaines (pp. 43-44). Lagos: Centre for Black and African Arts and Civilization.

Miyamoto, J. (2013). Introduction to Categorization Theory. [Online]

Retrieved from https://faculty.washington.edu/jmiyamot/p355/lec08-1.p355.spr14.pdf (June 6, 2014) Wa Thiong'o, N. (1986). Decolonising the Mind: The Politics of Language in African Literature. Portsmouth: Heinemann.

Wa Thiong'o, N. (2013). HardTalk Interview. [Online] Retrieved from https://www.youtube.com/watch?v=A9iNMIG5TH8 (July 2013).

Rosch, E. (1977). Classification of Real-World Objects: Origins and Representations in Cognition. In P.N. JohnsonLaird, \& P.C. Wason (Eds.), Thinking: Readings in Cognitive Science (pp. 212-222). Cambridge: University Press. Taylor, J. R. (2003). Linguistic Categorization. Oxford: University Press. Wittgenstein, L. (2001). Philosophical Investigations ( $3^{\text {rd }}$ ed.). Oxford: Blackwell.

\footnotetext{
${ }^{\mathrm{i}}$ I wish to thank my research assistant, Lydia Painter, for administering questionnaire in Vienna and London in 2014 to test the prototype theory with regards to the category "African languages". I also wish to thank my research assistant, Caroline Pajancic, for assisting with the formatting of this paper according to the ALLS style.

ii Bodomo, A. (2013). Lecture Notes on Language, Literacy, and Literature: The language question in African literary expression, Department of African Studies (Course no 140251), University of Vienna.

iii Bodomo, A. (2014). Survey Report on African Languages and Literatures, Unpublished manuscript, University of Vienna, Austria.
} 